F. Halperin - J. A. Beckman • M. E. Patti •

M. E. Trujillo • M. Garvin • M. A. Creager •

P. E. Scherer • A. B. Goldfine

\title{
The role of total and high-molecular-weight complex of adiponectin in vascular function in offspring whose parents both had type 2 diabetes
}

Received: 28 January 2005 / Accepted: 31 May 2005 / Published online: 10 August 2005

(C) Springer-Verlag 2005

\begin{abstract}
Aims/hypothesis: Adiponectin is an adipokine with insulin-sensitising and anti-atherogenic properties. We studied the role played by total adiponectin and by the bioactive high-molecular-weight (HMW) oligomeric complexes of adiponectin in vascular function in offspring whose parents both had type 2 diabetes, a population at high risk of diabetes and atherosclerosis. Methods: Total and \%HMW adiponectin, the cytokines $\mathrm{C}$-reactive protein, interleukin-6 and plasminogen activator inhibitor-1 (PAI-1), as well as lipid profiles were assayed in 19 offspring, each with two type 2 diabetic parents. Subjects underwent OGTTs and IVGTTs. Endothelium-dependent vasodilation (EDV) was assessed by brachial artery ultrasonography. Results: There was a significant relationship between $\% \mathrm{HMW}$ and total adiponectin levels $(r=0.72, p=0.001)$. Despite an expected strong positive correlation between HDL-cholesterol and adiponectin levels $(r=0.52, p=0.04)$, as well as HDL-cholesterol and $\operatorname{EDV}(r=0.56, p<0.02)$, there was no significant relationship between either total adiponectin or \% HMW adiponectin and EDV. Adiponectin was inversely associated with PAI- $1(r=0.50, p=0.05)$, but did not correlate with the inflammatory markers $\mathrm{C}$-re-
\end{abstract}

F. Halperin · J. A. Beckman · M. E. Patti · M. A. Creager A. B. Goldfine

Harvard Medical School,

Boston, MA, USA

F. Halperin - J. A. Beckman - M. A. Creager - A. B. Goldfine Brigham and Women's Hospital,

Boston, MA, USA

M. E. Patti · M. Garvin · A. B. Goldfine ( $\square)$

Joslin Diabetes Center,

One Joslin Place,

Boston, MA 02215, USA

e-mail: allison.goldfine@joslin.harvard.edu

Tel.: +1-617-7322643

Fax: +1-617-7133403

M. E. Trujillo · P. E. Scherer

Albert Einstein College of Medicine,

Bronx, NY, USA active protein or interleukin-6. Conclusions/interpretation. In offspring of diabetic parents, a population at high risk of diabetes and atherosclerotic disease, there is no relationship between total or \%HMW adiponectin and endotheliumdependent vasodilation. However, low adiponectin was associated with impaired fibrinolysis as manifested by increased levels of plasminogen activator inhibitor-1.

Keywords Adiponectin - Cardiovascular disease Endothelial function · High-density lipoprotein · Insulin resistance

Abbreviations AIRg: acute insulin secretory response to glucose - CRP: C-reactive protein - sCD40L: soluble CD40 ligand - EDV: endothelium-dependent vasodilation - EIV: endothelium-independent vasodilation $\cdot \mathrm{S}_{\mathrm{G}}$ : glucose effectiveness index $\cdot$ HMW: high molecular weight HOMA-IR: homeostasis model assessment-insulin resistance $\cdot S_{\mathrm{I}}$ : insulin sensitivity index $\cdot$ IL-6: interleukin 6 - LMW: low molecular weight - PAI-1: plasminogen activator inhibitor-1

\section{Introduction}

Type 2 diabetes mellitus is the most common metabolic disease and is increasing in prevalence worldwide such that the global burden of diabetes is estimated to double over the next 25 years $[1,2]$. Cardiovascular disease is the leading cause of morbidity and mortality for patients with type 2 diabetes. Atherosclerosis is frequently present at the time diabetes is first diagnosed, suggesting that the atherosclerotic process begins prior to the onset of overt diabetes [3]. Adiponectin is a recently described abundant adipocyte-secreted protein $[4,5]$ which has been suggested to have both insulin-sensitising and anti-atherogenic properties.

Adiponectin has been shown to have an inverse relationship to adiposity $[6,7]$ and to play a significant role in insulin action [6-10]. Persons with type 2 diabetes have lower levels of adiponectin than controls, independent of 
BMI [7, 11]. Heterozygous adiponectin-deficient mice exhibit mild insulin resistance, while homozygous deficiency is associated with more significant glucose intolerance and increased likelihood of diabetes, which can be reversed following adiponectin administration [5, 10, 12].

In addition to its role as a modulator of glucose metabolism, adiponectin also has anti-inflammatory and antiatherogenic properties. Epidemiologically, serum levels of the protein correlate negatively with cardiac risk factors, positively with HDL-cholesterol and are lower in patients with coronary artery disease than in controls [13-15]. Adiponectin accumulates in rat carotid artery walls after balloon injury, but not in healthy vessel walls [16] and has been shown to suppress both the conversion of macrophages to foam cells and the migration of smooth muscle cells $[6,17]$. Adiponectin-deficient mice develop severe neointimal hyperplasia, that can be attenuated by adiponectin repletion [18] and the protein protects apo-E deficient mice from development of atherosclerosis [19]. Furthermore, it has also been suggested to upregulate endothelial nitric oxide synthase expression and potentiate its enzymatic activity, thereby stimulating endothelial cell nitric oxide production [20].

Adiponectin structure is complex. The protein has an $\mathrm{N}$-terminal secretory signal sequence, a non-helical region, multiple collagen repeats and a C-terminal globular domain. It circulates in vivo both as low-molecularweight (LMW) homo-trimers and high-molecular-weight (HMW) oligomeric complexes consisting of 12-18 subunits $[21,22]$. The relative biological importance of the different components and the various aggregate forms of the protein are not fully understood. However, the HMW complex is thought to have enhanced biological activity compared with the LMW. At the clinical level, only the percentage of HMW protein exhibits an inverse correlation with coronary artery disease [23]. In vitro, formation of higher order multimers is necessary to promote AMPactivated protein kinase in hepatocytes [24].

Additional signalling complexity occurs at the level of the protein receptor. To date, two receptors have been cloned. AdipoR1 has high affinity for the globular domain of adiponectin and lower affinity for the full-length protein; it is abundantly expressed in muscle and more moderately so in other tissues (including endothelial cells). In contrast, AdipoR2 has intermediate affinity for both globular and full-length protein and is predominately expressed in the liver [19], with lower levels in other tissues. Different tissue distribution and functionality of the receptors may explain in part the different effects of the full-length and globular proteins and perhaps of the low- and high-molecular-weight complexes.

Given the experimental evidence supporting an antiatherogenic property of adiponectin, it has been proposed that a link between this protein and endothelial dysfunction may exist [25-28]. However, the nature of this association remains poorly characterised. Thus, we sought to evaluate the relationship between total and high-molecular-weight adiponectin and measures of vascular function in offspring whose parents both had type 2 diabetes. This group is at risk of diabetes $[29,30]$ and may have early atherosclerotic disease manifested as abnormal endothelial function $[31,32]$.

\section{Subjects, materials and methods}

The Institutional Review Boards of the Joslin Diabetes Center and Brigham and Women's Hospital approved the study. Written informed consent was obtained from all individuals prior to participation.

Nineteen subjects, each with two type 2 diabetic parents, participated. All subjects were healthy as judged by medical history, were normotensive as determined by office blood pressure and were non-smokers.

All participants were instructed to consume a standard high-carbohydrate diet (250-300 g/day) for 3 days prior to undergoing an OGTT. A 100-g glucose load was administered to maximise glucose and insulin excursion, and glucose and insulin levels were measured prior to and 30, 60, 90 and 120 min after glucose was administered. Each subject was considered non-diabetic based on the National Diabetes Data Group criteria for a 75-g load [29, 33].

On a subsequent day, participants underwent an insulinmodified frequently sampled IVGTT [34]. In brief, after an overnight fast and the collection of baseline samples, Dextrose $0.3 \mathrm{~g} / \mathrm{kg}$ was administered intravenously, followed 20 min later by the intravenous infusion of insulin $0.03 \mathrm{U} / \mathrm{kg}$ (Humulin R; Eli Lilly, Indianapolis, IN, USA). Samples were collected for insulin and glucose at 2, 3, 4, 5, $6,8,10,12,14,19,22,23,24,25,27,30,40,50,60,70$, $80,90,100,120,140,160$ and $180 \mathrm{~min}$ following the dextrose and analysed using the Bergman's Minimal Model, a computer-based method to assess plasma insulin and glucose dynamics during an IVGTT. The minimum model for glucose disposal and insulin dynamics yields assessments of insulin secretion and sensitivity, including the insulin sensitivity index $\left(S_{\mathrm{I}}\right)$ and the glucose effectiveness index $\left(S_{\mathrm{G}}\right)$ also known as insulin-independent glucose clearance. Insulin resistance was also determined using the homeostasis model assessment (HOMA-IR) method as described [35]. Both $S_{\mathrm{I}} \mathrm{SI}$ and HOMA-IR have been demonstrated to correlate with euglycaemic clamp measures of insulin sensitivity [36].

Vascular function studies The determination of endothelial function was performed in accordance with published guidelines [37]. Subjects were studied in a quiet, temperature controlled, dimly lit room, after resting supine for a minimum of $5 \mathrm{~min}$. High-resolution B-mode ultrasonography of the brachial artery was performed using a Toshiba Powervision 8000 (Toshiba America Medical Systems, Inc., Tustin, CA, USA) ultrasound machine and $7.5 \mathrm{MHz}$ linear array probe. The brachial artery was imaged longitudinally just proximal to the antecubital fossa. Transducer position was adjusted to obtain optimal images of the near and far wall of the intima. Images were simultaneously recorded on super VHS videotape. The video output and electrocardiographic signal of the ultrasound machine were connected to a computer equipped with a 
Data Translation frame-grabber video card, (Dataviz, Trumbull, CT, USA). The ' $\mathrm{R}$ ' wave on the electrocardiogram served as a trigger to acquire frames at end diastole. After baseline image acquisition, a sphygmomanometric cuff placed above the antecubital fossa was inflated to suprasystolic pressure $(200 \mathrm{~mm} \mathrm{Hg})$ for $5 \mathrm{~min}$. Upon cuff release, reactive hyperaemia causes flow to increase through the brachial artery subserving the forearm. Flowinduced, endothelium-dependent vasodilation (EDV) of the brachial artery was determined by acquiring images at $1 \mathrm{~min}$ after cuff deflation. Flow-mediated vasodilation at this time point is largely endothelium-dependent and nitric oxide mediated and can be inhibited by administration of the nitric oxide synthase antagonist, $N^{\mathrm{G}}$-monomethyl-Larginine [38]. Ten minutes after cuff release, the brachial artery was imaged again to ensure a return to basal conditions. Then, to determine endothelium-independent vasodilation (EIV), subjects received $0.4 \mathrm{mg}$ of nitroglycerin, sublingually. The brachial artery was imaged 3 min later. Nitroglycerine was not administered if the systolic blood pressure was below $100 \mathrm{~mm} \mathrm{Hg}$. Arterial diameter during each experimental condition was measured using edge detection software (Brachial Tools 4.2.2, Medical Imaging Applications LLC, Iowa City, IA, USA). Brachial artery blood flow velocity was determined via time-velocity integral measurement.

Assays Total plasma adiponectin levels were measured by RIA (LINCO Research). For the differential measurements of the complexes, plasma was size fractionated by velocity sedimentation analysis and adiponectin was quantitated by western blot analysis as previously described [39]. Following SDS-PAGE, proteins were transferred to BA83 nitrocellulose (Schleicher \& Schuell). An affinity-purified rabbit anti-adiponectin antibody raised against a peptide comprising the $\mathrm{N}$-terminal hypervariable region (EDDVT TEELAPALV, mouse; DQETTQGPGV, human) was used; these antibodies recognise a single band of $30 \mathrm{kD}$ by western blot analysis and have equal affinity for all oligomeric forms of protein. Blots were decorated with an ${ }^{125} \mathrm{I}$-derivatised secondary goat anti-rabbit antibody (Amersham Biosciences) and analysed with a Phosphor Imager. Fractions 4-6 (LMW hexamers) and 9-11 (HMW adiponectin) from velocity sedimentation were quantitated with Image-Quant software. The variable labelled per cent HMW adiponectin (\%HMW) in this manuscript represents $\mathrm{HMW} /(\mathrm{HMW}+\mathrm{LMW}) \times 100$, as quantitated by the above method [22].

Samples for glucose, glycohaemoglobin and lipids were performed using routine laboratory assays by the Joslin Diabetes Center clinical laboratory. In brief, glucose was measured by the glucose oxidase method (Synchron CX3delta), total cholesterol and HDL using a cholesterol esterase assay and triglycerides via hydrolysis to glycerol and NEFAs (Beckman Synchron CX9) (Beckman Coulter, Brea, CA, USA). Glycohaemoglobin was assessed by HPLC (Tosho 2.2; Tosoh Bioscience, San Francisco, CA, USA).

All immunoassays were performed in duplicate by commercial assay including serum insulin (Insulin RIA;
Diagnostic Systems Laboratories, Webster, TX, USA), CRP (hsCRP ELISA; Alpha Diagnostic International, San Antonio, TX, USA), interleukin-6 (Quantikine HS IL-6; R\&D Systems, Minneapolis, MN, USA) and plasma PAI-1 (Imubind Plasma PAI-1 ELISA; American Diagnostica, Stamford, CT, USA).

Statistical analysis Subject characteristics are presented as means \pm standard deviation. The Pearson's correlation and simple regression analysis were used to evaluate the correlation between measured variables and correlation coefficient $r$ is reported. Independent variables were assessed both as measured and after logarithm transformation for skewed distribution. Data results are considered significant with two-tailed $p$ values $<0.05$. Statistical analyses were carried out with the StatView program (StatView, SAS Institute, Cary, NC, USA).

\section{Results}

Baseline characteristics of the subjects are summarised in Table 1. No subject in this cohort had diabetes by either fasting glucose or by 2-h glucose concentration following the 100-g glucose load. However, nine subjects had 2-h glucose concentrations above $7.8 \mathrm{mmol} / 1(140 \mathrm{mg} / \mathrm{dl})$ but less than $11.1 \mathrm{mmol} / 1(200 \mathrm{mg} / \mathrm{dl})$, suggesting mild glucose intolerance and increased risk for development of diabetes. In all subjects, $\mathrm{HbA}_{1} \mathrm{c}$ was within the normal range (0.040.06). Two subjects did not have HMW adiponectin measurements due to insufficient sample and four subjects did not receive nitroglycerin for measurement of endothelial-

Table 1 Characteristics of study subjects

\begin{tabular}{ll}
\hline & $\begin{array}{l}\text { Mean } \pm \text { standard } \\
\text { deviation }\end{array}$ \\
\hline$n$ (male/female) & $19(9 / 10)$ \\
Age (years) & $38.3 \pm 8.7$ \\
BMI $\left(\mathrm{kg} / \mathrm{m}^{2}\right)$ & $27.0 \pm 4.4$ \\
Cholesterol (mmol/l) & $4.6 \pm 1.0$ \\
Triglyceride $(\mathrm{mmol} / \mathrm{l})$ & $1.1 \pm 0.6$ \\
HDL (mmol/l) & $1.4 \pm 0.4$ \\
Systolic blood pressure (mm Hg) & $119.2 \pm 18.5$ \\
Diastolic blood pressure (mm Hg) & $69.7 \pm 7.6$ \\
Fasting insulin (pmol/1) & $63.9 \pm 32.6$ \\
2-h insulin (pmol/l) & $835.5 \pm 682.0$ \\
Fasting glucose (mmol/l) & $5.3 \pm 0.6$ \\
2-h glucose (mmol/l) & $7.4 \pm 2.0$ \\
HbA ${ }_{1} \mathrm{c}($ Proportion of total & $0.05 \pm 0.004$ \\
haemoglobin) & \\
HOMA-IR ${ }^{\mathrm{a}}$ & $2.2 \pm 1.2$ \\
Adiponectin ( $\mu \mathrm{gg} / \mathrm{ml})$ & $23.2 \pm 17.6$ \\
HMW adiponectin $(\%)$ & $20.9 \pm 16.7$ \\
Endothelial-dependent vasodilation $(\%)$ & $7.1 \pm 0.04$ \\
Endothelial-independent vasodilation $(\%)$ & $18.9 \pm 0.06$ \\
\hline
\end{tabular}

${ }^{\mathrm{a}} H O M A-I R$ homeostasis model assessment of insulin resistance ${ }^{\mathrm{b}} H M W$ high molecular weight 


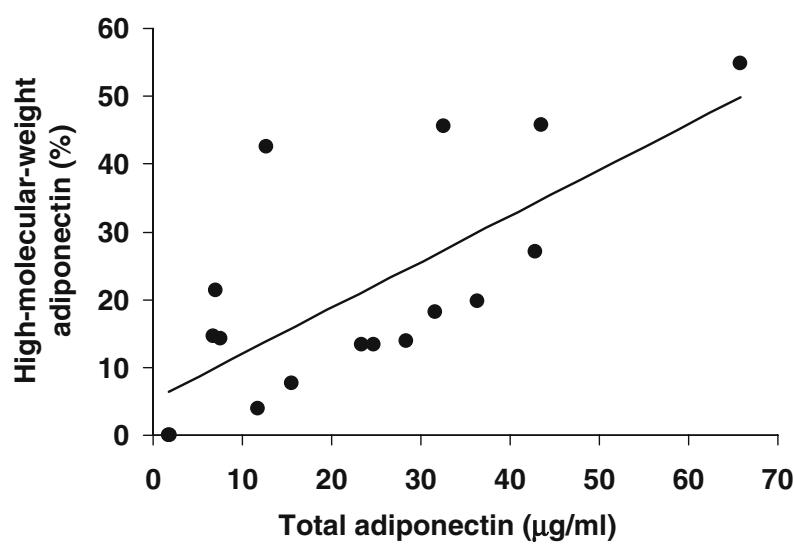

Fig. 1 There is a strong positive association between \%HMW and total adiponectin $(r=0.72, p=0.001)$

independent vasodilation because their systolic blood pressure was less than $100 \mathrm{~mm} \mathrm{Hg}$.

The mean adiponectin level was $23.2 \pm 17.6 \mu \mathrm{g} / \mathrm{ml}$ and mean \%HMW adiponectin was $20.9 \pm 16.7 \%$. The relationship between total and \%HMW adiponectin was signifi-
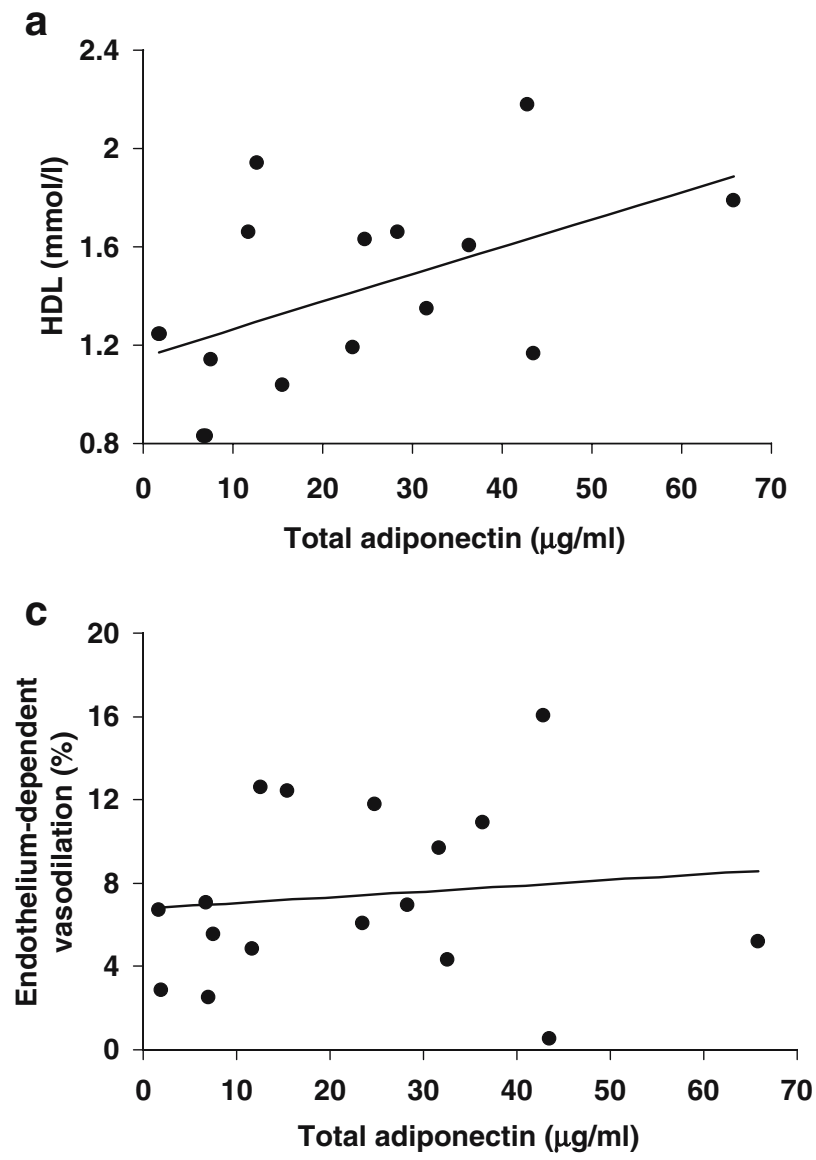

Fig. 2 a In offspring of diabetic parents, HDL-cholesterol correlates highly with adiponectin $(r=0.52, p=0.04)$. b There is a strong positive relationship between HDL-cholesterol levels and EDV $(r=0.56, p=0.02)$. c In offspring whose parents are both diabetic, there is no significant correlation between total adiponectin levels cantly and positively correlated $(r=0.72, p=0.001)$ (Fig. 1$)$, a finding that has not previously been reported.

As expected, adiponectin levels correlated with measurements of insulin sensitivity but not direct measures of glycaemia. HOMA-IR calculated from the fasting glucose and insulin measures exhibited an inversely proportional relationship to total $(r=0.53, p=0.04)$ and \%HMW adiponectin $(r=0.71, p<0.003)$, as did $S_{\mathrm{I}}$ measured dynamically during IVGTT (\%HMW, $r=0.89, p<0.0001)$. Total and \%HMW adiponectin were not related to the insulinindependent glucose disposal measure $S_{\mathrm{G}}$, nor to fasting glucose, 2-h glucose, or glycohaemoglobin.

We demonstrated a strong relationship between adiponectin levels and HDL-cholesterol $(r=0.52, p=0.04)$ (Fig. 2a). Likewise, HDL-cholesterol levels showed a strong positive relationship to EDV $(r=0.56, p<0.02)$ (Fig. $2 b)$. However, despite the inter-relationships between adiponectin and HDL-cholesterol and HDL and EDV, there was no significant correlation between either total adiponectin levels and EDV ( $p=0.70)$ (Fig. 2c) or \%HMW adiponectin and EDV ( $p=0.70)$ (Fig. 2d). Similarly, there was no correlation between total or \%HMW adiponectin levels and EIV $(p \geq 0.5)$.
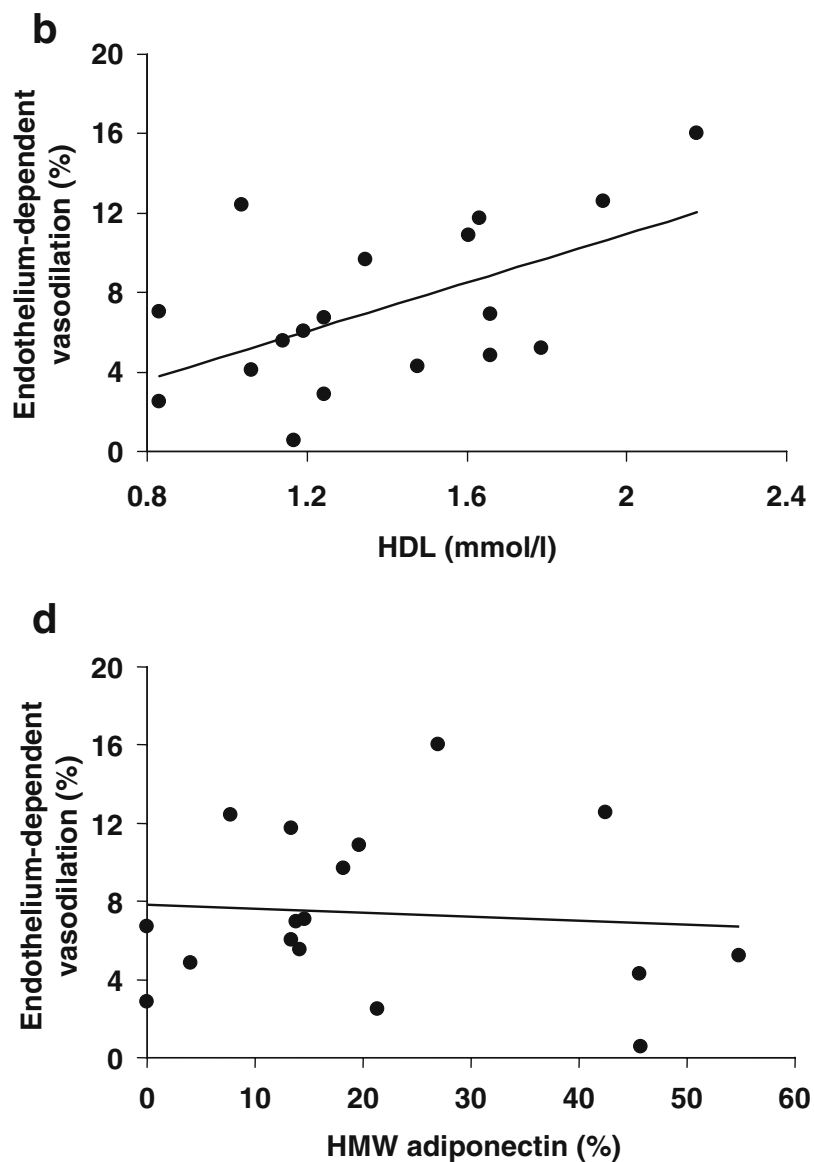

and endothelium-dependent vasodilation $(p=0.7)$. d The HMW oligomeric isomer of adiponectin is biologically active. However, there is no significant association between \%HMW adiponectin and endothelium-dependent vasodilation $(p=0.76)$ 


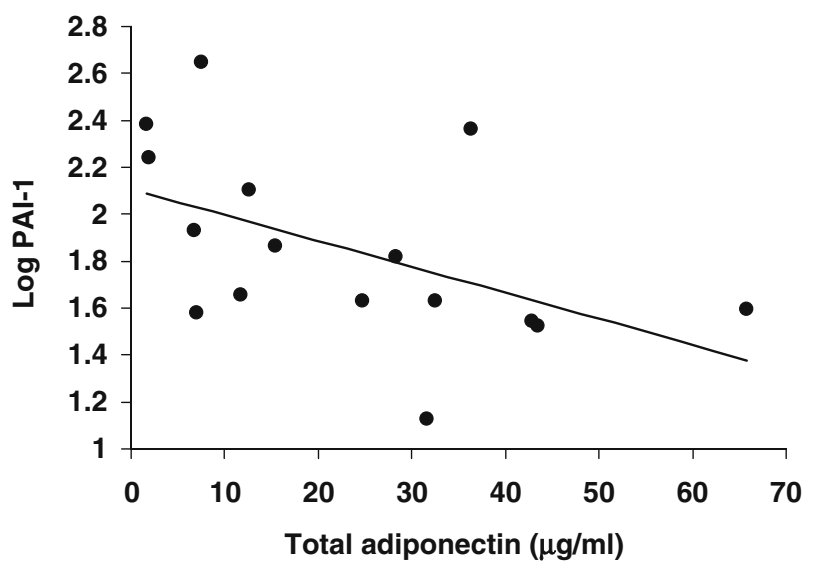

Fig. 3 PA1-1 was increased in persons with incident diabetes and atherosclerosis. An inverse relationship between adiponectin and PAI-1 levels ( $\log$ transformed for skewed distribution) $(r=0.50$, $p=0.05$ ) is present in offspring of diabetic parents

We calculated a total HMW index by multiplying \%HMW by total adiponectin measured by RIA. Using the total HMW index or \%HMW for correlations with other variables produced similar results and therefore data from these additional calculations is not reported.

As the inflammatory cytokines/adipokines CRP, IL-6 and plasminogen activator inhibitor 1 (PAI-1) have been suggested to be elevated in persons at risk of developing diabetes and cardiovascular events [40-42], we sought to evaluate the relationship between total or \%HMW adiponectin and these inflammatory markers. Adiponectin levels were associated with impaired fibrinolysis and inversely correlated with PAI-1 (after log transformation for skewed distribution) $(r=0.50, p=0.05)$ (Fig. 3), although we found no significant correlation with inflammatory markers CRP $(p=0.83)$ or IL-6 $(p=0.50)$.

\section{Discussion}

There is an epidemic of obesity and type 2 diabetes worldwide, and cardiovascular disease is the leading cause of morbidity and mortality in diabetic patients. Adiponectin, a relatively novel serum protein produced uniquely by adipocytes, has been studied in a variety of contexts in vivo and in vitro and is proposed to have anti-diabetic, antiinflammatory and anti-atherogenic properties. Thus, we evaluated the role of total and \%HMW adiponectin in vascular function in offspring whose parents both had type 2 diabetes, a group at high risk of developing diabetes [29, 30]. The study cohort was highly enriched for progression to diabetes, as half of subjects had early glucose intolerance to provocative testing in addition to low insulin sensitivity and glucose effectiveness. The endothelium plays a pivotal role in the pathogenesis of atherosclerosis, and impaired endothelial function is considered an early marker for vascular disease [43-46]. Offspring of diabetic parents are not only at risk for progression to diabetes, they have also previously been suggested to have diminished endothelial function $[31,32]$. We restricted our analysis to a diabetesprone group as the relatively narrow range of adiponectin and endothelial function in a solely healthy population could miss an important relationship that might be better revealed during progression from normal to the early pathologic state. Thus, this cohort is well suited for assessment of changes associated with early pathophysiology linking the two conditions and it would be particularly clinically relevant to have a predictive marker of both diseases in this high-risk population.

We found a significant relationship between adiponectin levels and measures of insulin sensitivity, including HOMAIR and the insulin sensitivity index derived from an IVGTT. Furthermore, we corroborated the strong relationship previously described between adiponectin and HDLcholesterol [13, 47, 48]. HDL-cholesterol is an important predictor of endothelial function [49-53]. Indeed, there was a correlation between HDL levels and EDV in our subjects. Despite these inter-relationships, however, there was no significant correlation between total or \%HMW adiponectin and flow-stimulated endothelium-dependent vasodilation, a clinically accepted estimate of endothelial function.

As adiponectin is related to both insulin resistance and vascular physiology, other investigators have looked at the relationship between adiponectin and EDV as an experimental marker for clinical atherosclerotic disease. If such a correlation were established, adiponectin could potentially be used as a biomarker to identify at-risk populations for targeted therapy as well as to monitor therapeutic interventions. Studies of the association between adiponectin levels and vascular reactivity have been inconclusive in both normal and hyperglycaemic populations. A positive relationship between adiponectin and peak forearm blood flow was found in both healthy [25] and hypertensive Japanese subjects [26]. Tan et al. described a positive relationship between adiponectin and EDV both in healthy and in type 2 diabetic persons [27]. In contrast, Singhal et al. [54] reported no correlation between flow-mediated endothelial-dependent vasodilation and adiponectin in adolescents with normal BMI, and Fernandez-Real et al. found no correlation between adiponectin in EDV in persons with either normal or impaired glucose tolerance [28]. Similarly, in this study we found non-diabetic offspring of parents with type 2 diabetes, who are at increased risk for development of diabetes and atherosclerosis, exhibit no relationship between adiponectin, or HMW adiponectin and EDV.

Per cent HMW adiponectin has been postulated to be the most accurate measurement of the biologically active form of the protein. Indeed, the HMW isomer exhibits a stronger relationship to incident coronary artery disease [23] as well as to the insulin sensitising response to thiazolidinedione administration [22]. Furthermore only HMW adiponectin has been shown to suppresses apoptosis of endothelial cells [23], and formation of higher order complexes is necessary to promote AMP-activated protein kinase in hepatocytes [24]. Given these collective findings, it seems possible that studying total adiponectin may be insufficient to detect a potential relationship to vascular function and we chose to 
specifically assess the role of the HMW complexes in vascular function in vivo. However, in a population at risk for diabetes and atherosclerosis, we found no significant association between \%HMW adiponectin and endotheliummediated dilation.

One important question raised by our findings is why the studies that explore the relationship between adiponectin and vascular function have shown inconsistent results. Although it is possible that our sample size is too small to detect a relationship between adiponectin and vascular function, it is also possible that there are ethnic, environmental, or disease-related differences in endothelial response to adiponectin among the different study populations. Some evidence exists that there are racial differences in levels of adiponectin [55]. Alternatively, hyperglycaemia, which has been demonstrated to attenuate endothelial function $[56,57]$, may modulate the relationship between adiponectin and EDV, although we found no direct relationship between adiponectin and multiple measures of glycaemic burden, including fasting, 2-h glucose and glycohaemoglobin.

Additionally, it is important to consider the role of HDL in the inter-relationship between adiponectin and endothelial function. Our study demonstrates that in offspring of diabetic parents HDL-cholesterol correlates highly with adiponectin, an association previously reported in healthy $[13,14]$, obese [47] and type 2 diabetic subjects [48]. The link between HDL-cholesterol and EDV that we demonstrate is well established: multiple studies show low HDLcholesterol is highly predictive of endothelial dysfunction in healthy and diabetic subjects [49-53], and in experimental models where HDL-cholesterol is raised acutely, EDV normalises [58]. Thus, the role of HDL-cholesterol as a potential confounder in the relationship between adiponectin and endothelial function in vivo may not have been adequately considered in previous reports [25, 27]. In future studies, the relationship between adiponectin and EDV needs to be carefully controlled for HDL-cholesterol, which correlates highly with both adiponectin and EDV and is therefore a potential important confounding variable.

Our study also shows that the correlation between \%HMW adiponectin and total adiponectin is very high. This relationship suggests synchronous regulation. As described above, experimental evidence suggests that \%HMW may be the more active form of the protein. At the same time, the technical assays required to measure \%HMW adiponectin are considerably more complicated and costly than those used to measure total adiponectin. In light of this and given the significant association we demonstrate between \%HMW and total adiponectin, it may be adequate to follow total adiponectin when simplicity and cost must be taken into consideration.

Finally, the cytokines/adipokines CRP, IL-6 and PAI-1 are increased in persons with incident diabetes and atherosclerosis [40-42]. Furthermore, low adiponectin may be associated with enhanced activity of the fibrinolytic pathway in other populations at risk for diabetes, including prior gestational diabetes, hypertension, obesity and coronary artery disease [59-61]. Thus, we sought to determine if adiponectin is related to PAI-1, CRP and IL-6 levels in offspring whose parents both have type 2 diabetes. We indeed found an inverse association between adiponectin and PAI-1. However, there was no significant correlation with CRP and IL-6, suggesting that these at-risk adipokines are not co-regulated. Although our study does not elucidate whether the mechanism underlying the interaction between fibrinolysis and adiponectin is direct or indirect, adiponectin has vasoprotective properties whereas PAI-1 promotes vascular events [62], so their inverse relationship implies that dysregulation of both protective and injurious molecules contributes to the development of vascular disease. Altered expression of these adipokines could underlie early atherosclerotic events in offspring of type 2 diabetic parents and contribute to the high incidence of atherosclerosis at the time of diagnosis of diabetes.

In conclusion, we studied offspring whose parents both had type 2 diabetes, a healthy cohort at very high risk for the development of diabetes and cardiovascular disease, in which a predictive biomarker for these disorders would therefore be particularly pertinent. However, we found no correlation between total or \%HMW adiponectin levels and endothelium-dependent vasodilation, a clinical marker for endothelial dysfunction. Given previous findings of significant associations between these variables in cohorts with different subject characteristics, we postulate that there may be ethnic, environmental or disease-specific differences in the interaction between adiponectin and the endothelium, and further research needs to be done to elucidate the nature of such differences. The inverse relationship seen between adiponectin and PAI-1 suggests imbalance between protective and detrimental pathways in high-risk persons. Longitudinal, rather than cross-sectional studies may provide additional predictive information, as changes in levels over time, rather than absolute levels, may provide important information for disease development.

Acknowledgements Supported by NIH K23-DK02795, RO1 062948, P01 HL48743 and M01 RR001032. M. A. Creager is the Simon C. Fireman Scholar in Cardiovascular Medicine at the Brigham and Women's Hospital.

\section{References}

1. King H, Aubert RE, Herman WH (1998) Global burden of diabetes, 1995-2025: prevalence, numerical estimates, and pro jections. Diabetes Care 21:1414-1431

2. Amos AF, McCarty DJ, Zimmet P (1997) The rising global burden of diabetes and its complications: estimates and projections to the year 2010. Diabet Med 14(Suppl 5):S1-S85

3. Hu FB, Stampfer MJ, Haffner SM, Solomon CG, Willett WC, Manson JE (2002) Elevated risk of cardiovascular disease prior to clinical diagnosis of type 2 diabetes. Diabetes Care 25:11291134

4. Scherer PE, Williams S, Fogliano M, Baldini G, Lodish HF (1995) A novel serum protein similar to C1q, produced exclusively in adipocytes. J Biol Chem 270:26746-26749

5. Maeda K, Okubo K, Shimomura I, Funahashi T, Matsuzawa Y, Matsubara K (1996) cDNA cloning and expression of a novel adipose specific collagen-like factor, apM1 (AdiPose Most abundant Gene transcript 1). Biochem Biophys Res Commun 221:286-289 
6. Arita Y, Kihara S, Ouchi N, Takahashi M, Maeda K, Miyagawa J, Hotta K, Shimomura I, Nakamura T, Miyaoka K et al (1999) Paradoxical decrease of an adipose-specific protein, adiponectin, in obesity. Biochem Biophys Res Commun 257:79-83

7. Hotta K, Funahashi T, Arita Y, Takahashi M, Matsuda M, Okamoto Y, Iwahashi H, Kuriyama H, Ouchi N, Maeda K et al (2000) Plasma concentrations of a novel, adipose-specific protein, adiponectin, in type 2 diabetic patients. Arterioscler Thromb Vasc Biol 20:1595-1599

8. Ouchi N, Kihara S, Arita Y, Maeda K, Kuriyama H, Okamoto Y, Hotta K, Nishida M, Takahashi M, Nakamura T et al (1999) Novel modulator for endothelial adhesion molecules: adipocyte-derived plasma protein adiponectin. Circulation 100:24732476

9. Berg AH, Combs TP, Du X, Brownlee M, Scherer PE (2001) The adipocyte-secreted protein Acrp30 enhances hepatic insulin action. Nat Med 7:947-953

10. Yamauchi T, Kamon J, Waki H, Terauchi Y, Kubota N, Hara K, Mori Y, Ide T, Murakami K, Tsuboyama-Kasaoka N et al (2001) The fat-derived hormone adiponectin reverses insulin resistance associated with both lipoatrophy and obesity. Nat Med 7:941-946

11. Daimon M, Oizumi T, Saitoh T, Kameda W, Hirata A, Yamaguchi H, Ohnuma H, Igarashi M, Tominaga M, Kato T (2003) Decreased serum levels of adiponectin are a risk factor for the progression to type 2 diabetes in the Japanese Population: the Funagata study. Diabetes Care 26:2015-2020

12. Kubota N, Terauchi Y, Yamauchi T, Kubota T, Moroi M, Matsui J, Eto K, Yamashita T, Kamon J, Satoh H et al (2002) Disruption of adiponectin causes insulin resistance and neointimal formation. J Biol Chem 277:25863-25866

13. Kazumi T, Kawaguchi A, Hirano T, Yoshino G (2004) Serum adiponectin is associated with high-density lipoprotein cholesterol, triglycerides, and low-density lipoprotein particle size in young healthy men. Metabolism 53:589-593

14. Kazumi T, Kawaguchi A, Sakai K, Hirano T, Yoshino G (2002) Young men with high-normal blood pressure have lower serum adiponectin, smaller LDL size, and higher elevated heart rate than those with optimal blood pressure. Diabetes Care 25:971976

15. Pischon T, Girman CJ, Hotamisligil GS, Rifai N, Hu FB, Rimm EB (2004) Plasma adiponectin levels and risk of myocardial infarction in men. JAMA 291:1730-1737

16. Okamoto Y, Arita Y, Nishida M, Muraguchi M, Ouchi N, Takahashi M, Igura T, Inui Y, Kihara S, Nakamura T et al (2000) An adipocyte-derived plasma protein, adiponectin, adheres to injured vascular walls. Horm Metab Res 32:47-50

17. Ouchi N, Kihara S, Arita Y, Nishida M, Matsuyama A, Okamoto Y, Ishigami M, Kuriyama H, Kishida K, Nishizawa H et al (2001) Adipocyte-derived plasma protein, adiponectin, suppresses lipid accumulation and class A scavenger receptor expression in human monocyte-derived macrophages. Circulation 103:1057-1063

18. Matsuda M, Shimomura I, Sata M, Arita Y, Nishida M, Maeda $\mathrm{N}$, Kumada M, Okamoto Y, Nagaretani H, Nishizawa $\mathrm{H}$ et al (2002) Role of adiponectin in preventing vascular stenosis. The missing link of adipo-vascular axis. J Biol Chem 277:3748737491

19. Yamauchi T, Kamon J, Ito Y, Tsuchida A, Yokomizo T, Kita S, Sugiyama T, Miyagishi M, Hara K, Tsunoda M et al (2003) Cloning of adiponectin receptors that mediate antidiabetic metabolic effects. Nature 423:762-769

20. Chen H, Montagnani M, Funahashi T, Shimomura I, Quon MJ (2003) Adiponectin stimulates production of nitric oxide in vascular endothelial cells. J Biol Chem 278:45021-45026

21. Nakano Y, Tobe T, Choi-Miura NH, Mazda T, Tomita M (1996) Isolation and characterization of GBP28, a novel gelatin-binding protein purified from human plasma. J Biochem (Tokyo) 120:803-812
22. Pajvani UB, Hawkins M, Combs TP, Rajala MW, Doebber T, Berger JP, Wagner JA, Wu M, Knopps A, Xiang AH et al (2004) Complex distribution, not absolute amount of adiponectin, correlates with thiazolidinedione-mediated improvement in insulin sensitivity. J Biol Chem 279:12152-12162

23. Kobayashi H, Ouchi N, Kihara S, Walsh K, Kumada M, Abe Y, Funahashi T, Matsuzawa Y (2004) Selective suppression of endothelial cell apoptosis by the high molecular weight form of adiponectin. Circ Res 94:e27-e31

24. Waki H, Yamauchi T, Kamon J, Ito Y, Uchida S, Kita S, Hara K, Hada Y, Vasseur F, Froguel P et al (2003) Impaired multimerization of human adiponectin mutants associated with diabetes. Molecular structure and multimer formation of adiponectin. J Biol Chem 278:40352-40363

25. Shimabukuro M, Higa N, Asahi T, Oshiro Y, Takasu N, Tagawa T, Ueda S, Shimomura I, Funahashi T, Matsuzawa Y (2003) Hypoadiponectinemia is closely linked to endothelial dysfunction in man. J Clin Endocrinol Metab 88:3236-3240

26. Ouchi N, Ohishi M, Kihara S, Funahashi T, Nakamura T, Nagaretani H, Kumada M, Ohashi K, Okamoto Y, Nishizawa H et al (2003) Association of hypoadiponectinemia with impaired vasoreactivity. Hypertension 42:231-234

27. Tan KC, Xu A, Chow WS, Lam MC, Ai VH, Tam SC, Lam KS (2004) Hypoadiponectinemia is associated with impaired endothelium-dependent vasodilation. J Clin Endocrinol Metab 89: 765-769

28. Fernandez-Real JM, Castro A, Vazquez G, Casamitjana R, Lopez-Bermejo A, Penarroja G, Ricart W (2004) Adiponectin is associated with vascular function independent of insulin sensitivity. Diabetes Care 27:739-745

29. Martin BC, Warram JH, Krolewski AS, Bergman RN, Soeldner JS, Kahn CR (1992) Role of glucose and insulin resistance in development of type 2 diabetes mellitus: results of a 25 -year follow-up study. Lancet 340:925-929

30. Goldfine AB, Bouche C, Parker RA, Kim C, Kerivan A, Soeldner JS, Martin BC, Warram JH, Kahn CR (2003) Insulin resistance is a poor predictor of type 2 diabetes in individuals with no family history of disease. Proc Natl Acad Sci U S A 100:2724-2729

31. Caballero AE, Arora S, Saouaf R, Lim SC, Smakowski P, Park JY, King GL, LoGerfo FW, Horton ES, Veves A (1999) Microvascular and macrovascular reactivity is reduced in subjects at risk for type 2 diabetes. Diabetes 48:1856-1862

32. Balletshofer BM, Rittig K, Enderle MD, Volk A, Maerker E, Jacob S, Matthaei S, Rett K, Haring HU (2000) Endothelial dysfunction is detectable in young normotensive first-degree relatives of subjects with type 2 diabetes in association with insulin resistance. Circulation 101:1780-1784

33. National Diabetes Data Group (1979) Classification and diagnosis of diabetes mellitus and other categories of glucose intolerance. Diabetes 28:1039-1057

34. Bergman RN (1989) Lilly lecture 1989. Toward physiological understanding of glucose tolerance. Minimal-model approach. Diabetes 38:1512-1527

35. Matthews DR, Hosker JP, Rudenski AS, Naylor BA, Treacher DF, Turner RC (1985) Homeostasis model assessment: insulin resistance and beta-cell function from fasting plasma glucose and insulin concentrations in man. Diabetologia 28:412-419

36. Bonora E, Targher G, Alberiche M, Bonadonna RC, Saggiani F, Zenere MB, Monauni T, Muggeo M (2000) Homeostasis model assessment closely mirrors the glucose clamp technique in the assessment of insulin sensitivity: studies in subjects with various degrees of glucose tolerance and insulin sensitivity. Diabetes Care 23:57-63

37. Corretti MC, Anderson TJ, Benjamin EJ, Celermajer D, Charbonneau F, Creager MA, Deanfield J, Drexler H, GerhardHerman M, Herrington D et al (2002) Guidelines for the ultrasound assessment of endothelial-dependent flow-mediated vasodilation of the brachial artery: a report of the International Brachial Artery Reactivity Task Force. J Am Coll Cardiol 39: 257-265 
38. Lieberman EH, Gerhard MD, Uehata A, Selwyn AP, Ganz P, Yeung AC, Creager MA (1996) Flow-induced vasodilation of the human brachial artery is impaired in patients $<40$ years of age with coronary artery disease. Am J Cardiol 78:1210-1214

39. Pajvani UB, Du X, Combs TP, Berg AH, Rajala MW, Schulthess T, Engel J, Brownlee M, Scherer PE (2003) Structure-function studies of the adipocyte-secreted hormone Acrp30/adiponectin. Implications fpr metabolic regulation and bioactivity. J Biol Chem 278:9073-9085

40. Pradhan AD, Manson JE, Rifai N, Buring JE, Ridker PM (2001) C-reactive protein, interleukin 6 , and risk of developing type 2 diabetes mellitus. JAMA 286:327-334

41. Thorand B, Lowel H, Schneider A, Kolb H, Meisinger C, Frohlich M, Koenig W (2003) C-reactive protein as a predictor for incident diabetes mellitus among middle-aged men: results from the MONICA Augsburg cohort study, 1984-1998. Arch Intern Med 163:93-99

42. Festa A, D'Agostino R Jr, Tracy RP, Haffner SM (2002) Elevated levels of acute-phase proteins and plasminogen activator inhibitor-1 predict the development of type 2 diabetes: the insulin resistance atherosclerosis study. Diabetes 51:1131-1137

43. Harrison DG (1994) Endothelial dysfunction in atherosclerosis. Basic Res Cardiol 89(Suppl 1):87-102

44. Kuvin JT, Karas RH (2003) Clinical utility of endothelial function testing: ready for prime time? Circulation 107:3243-3247

45. Quyyumi AA (2003) Prognostic value of endothelial function. Am J Cardiol 91:19H-24H

46. Gokce N, Keaney JF Jr, Hunter LM, Watkins MT, Nedeljkovic ZS, Menzoian JO, Vita JA (2003) Predictive value of noninvasively determined endothelial dysfunction for long-term cardiovascular events in patients with peripheral vascular disease. J Am Coll Cardiol 41:1769-1775

47. Baratta R, Amato S, Degano C, Farina MG, Patane G, Vigneri R, Frittitta L (2004) Adiponectin relationship with lipid metabolism is independent of body fat mass: evidence from both crosssectional and intervention studies. J Clin Endocrinol Metab 89: 2665-2671

48. Schulze MB, Rimm EB, Shai I, Rifai N, Hu FB (2004) Relationship between adiponectin and glycemic control, blood lipids, and inflammatory markers in men with type 2 diabetes. Diabetes Care 27:1680-1687

49. Steer P, Hulthe J, Miligard J, Sarabi DM, Basu S, Vessby B, Lind L (2002) Endothelial vasodilatory function is predicted by circulating apolipoprotein B and HDL in healthy humans. Lipids 37:1135-1140

50. Toikka JO, Ahotupa M, Viikari JS, Niinikoski H, Taskinen M, Irjala K, Hartiala JJ, Raitakari OT (1999) Constantly low HDLcholesterol concentration relates to endothelial dysfunction and increased in vivo LDL-oxidation in healthy young men. Atherosclerosis 147:133-138
51. Chan NN, Colhoun HM, Vallance P (2001) Cardiovascular risk factors as determinants of endothelium-dependent and endothelium-independent vascular reactivity in the general population. J Am Coll Cardiol 38:1814-1820

52. O'Brien SF, Watts GF, Playford DA, Burke V, O'Neal DN, Best JD (1997) Low-density lipoprotein size, high-density lipoprotein concentration, and endothelial dysfunction in non-insulindependent diabetes. Diabet Med 14:974-978

53. Li XP, Zhao SP, Zhang XY, Liu L, Gao M, Zhou QC (2000) Protective effect of high density lipoprotein on endotheliumdependent vasodilatation. Int J Cardiol 73:231-236

54. Singhal A, Jamieson N, Fewtrell M, Deanfield J, Lucas A, Sattar N (2005) Adiponectin predicts insulin resistance but not endothelial function in young healthy adolescents. J Clin Endocrinol Metab (in press)

55. Retnakaran R, Hanley AJ, Raif N, Connelly PW, Sermer M, Zinman B (2004) Hypoadiponectinaemia in South Asian women during pregnancy: evidence of ethnic variation in adiponectin concentration. Diabet Med 21:388-392

56. Williams SB, Cusco JA, Roddy MA, Johnstone MT, Creager MA (1996) Impaired nitric oxide-mediated vasodilation in patients with non-insulin-dependent diabetes mellitus. J Am Coll Cardiol 27:567-574

57. Williams SB, Goldfine AB, Timimi FK, Ting HH, Roddy MA, Simonson DC, Creager MA (1998) Acute hyperglycemia attenuates endothelium-dependent vasodilation in humans in vivo. Circulation 97:1695-1701

58. Bisoendial RJ, Hovingh GK, Levels JH, Lerch PG, Andresen I, Hayden MR, Kastelein JJ, Stroes ES (2003) Restoration of endothelial function by increasing high-density lipoprotein in subjects with isolated low high-density lipoprotein. Circulation 107:2944-2948

59. Skurk T, van Harmelen V, Lee YM, Wirth A, Hauner H (2002) Relationship between IL-6, leptin and adiponectin and variables of fibrinolysis in overweight and obese hypertensive patients. Horm Metab Res 34:659-663

60. Winzer C, Wagner O, Festa A, Schneider B, Roden M, Bancher-Todesca D, Pacini G, Funahashi T, Kautzky-Willer A (2004) Plasma adiponectin, insulin sensitivity, and subclinical inflammation in women with prior gestational diabetes mellitus. Diabetes Care 27:1721-1727

61. Maruyoshi H, Kojima S, Funahashi T, Miyamoto S, Hokamaki J, Soejima H, Sakamoto T, Kawano H, Yoshimura M, Kitagawa A et al (2004) Adiponectin is inversely related to plasminogen activator inhibitor type 1 in patients with stable exertional angina. Thromb Haemost 91:1026-1030

62. Alessi MC, Peiretti F, Morange P, Henry M, Nalbone G, JuhanVague I (1997) Production of plasminogen activator inhibitor 1 by human adipose tissue: possible link between visceral fat accumulation and vascular disease. Diabetes 46:860-867 